\title{
ON THE ARITHMETIC-GEOMETRIC MEAN INEQUALITY
}

\author{
Mohammad Sababheh, Shigeru Furuichi, \\ Zahra Heydarbeygi AND Hamid ReZa Moradi
}

Abstract. In this article, we present a new treatment of the arithmetic-geometric mean inequality and its siblings, the Heinz and the Young inequalities. New refinements via calculus computations and convex analysis are presented and a new Heinz-type inequality is presented for any symmetric operator mean.

Mathematics subject classification (2020): Primary 26E60, 26A51; Secondary 47A64, 47B15.

Keywords and phrases: Positive real numbers, arithmetic-geometric mean inequality, Heinz mean, convex function.

\section{REFERENCES}

[1] S. Furuichi AND H. R. Moradi, On further refinements for Young inequalities, Open Math. 16 (2018), 1478-1482.

[2] S. Furuichi, H. R. Moradi And M. SABABheh, New sharp inequalities for operator means, Linear Multilinear Algebra 67 (8) (2019), 1567-1578.

[3] I. H. GÜMÜş, H. R. Moradi AND M. SABABHeH, More accurate operator means inequalities, J. Math. Anal. Appl. 465 (2018), 267-280.

[4] F. Kittaneh And M. KRnić, Refined Heinz operator inequalities, Linear Multilinear Algebra 61 (8) (2013), 1148-1157.

[5] F. Kittaneh And Y. ManasRah, Improved Young and Heinz inequalities for matrices, J. Math. Anal. Appl. 361 (2010), 262-269.

[6] F. KitTANEH AND Y. MANASRAH, Reverse Young and Heinz inequalities for matrices, Linear Multilinear Algebra 59 (9) (2011), 1031-1037.

[7] H. R. Moradi, S. Furuichi, F. C. Mitroi And R. Naseri, An extension of Jensen's operator inequality and its application to Young inequality, Rev. R. Acad. Cienc. Exactas Fís. Nat. Ser. A Mat. 113 (2) (2019), 605-614.

[8] M. SABABHEH, Convexity and matrix means, Linear Algebra Appl. 506 (2016), 588-602.

[9] M. SABABHEH, Integral inequalities of the Heinz means as convex functions, J. Math. Inequal. 10 (2) (2016), 313-325.

[10] M. Sababheh and H. R. Moradi, Radical convex functions, Medit. J. Math. 18, 137 (2021), https://doi.org/10.1007/s00009-021-01784-8.

[11] M. SABABheh, A. Yousef, AND R. KhaliL, Interpolated young and Heinz inequalities, Linear Multilinear Algebra 63 (11) (2015), 2232-2244. 